\title{
O CONTRIBUTO DAS TECNOLOGIAS NO DESENVOLVIMENTO DO CURRICULO ESCOLAR: PERSPECTIVAS DOS ALUNOS
}

\author{
LA CONTRIBUCIÓN DE LAS TECNOLOGÍAS EN EL DESARROLLO DEL \\ CURRÍCULUM ESCOLAR: PERSPECTIVAS DE LOS ALUMNOS
}

\section{THE CONTRIBUTION OF TECHNOLOGIES IN THE DEVELOPMENT OF THE SCHOOL CURRICULUM: STUDENTS' PERSPECTIVES}

Teresa Paulino SANTOS ${ }^{1}$

Maria Palmira ALVES ${ }^{2}$

RESUMO: Este artigo apresenta os resultados de um estudo que identifica as perspetivas dos alunos do ensino básico sobre o contributo das tecnologias no desenvolvimento do currículo escolar. As Tecnologias da Informação e da Comunicação (TIC) são uma componente do currículo de caráter transversal, de acordo com a legislação em vigor portuguesa (despacho normativo $n .^{\circ} 1-\mathrm{F} / 2016$, artigo $3 .^{\circ}$ ), sendo objeto de avaliação nas diversas disciplinas, de acordo com critérios definidos pelo conselho pedagógico de cada agrupamento $^{3}$. As investigações têm salientado o contributo das tecnologias na melhoria das aprendizagens dos alunos e no sucesso escolar. Contudo, as perspetivas dos alunos são pouco investigadas, pelo que este estudo tem como objetivo compreender as perspetivas dos alunos do ensino básico sobre esta problemática. Os dados foram recolhidos através de inquérito por questionário, junto de alunos $(n=233)$ do Ensino Básico, tratados com recurso ao SPSS (Statistic Package for Social Sciences, v.21) e utilizada a estatística descritiva para a sua análise. Os alunos referem que utilizam as tecnologias para fins diversos: aceder ao email, arquivar documentos, utilizar a plataforma moodle e consultar a website da escola. Apesar da sua frequência ser ainda reduzida, consideram que o recurso às TIC permite concluir as tarefas escolares mais rapidamente, facilita a colaboração entre alunos e professores, tornando-a também mais eficaz com os encarregados de educação, melhora as aprendizagens e, consequentemente, intervém no sucesso educativo.

PALAVRAS-CHAVE: Tecnologias da informação e da comunicação. Ensino básico. Currículo escolar. Sucesso.

RESUMEN: Este artículo presenta los resultados de un estudio, que identifica las perspectivas de los alumnos de la enseñanza básica sobre la contribución de las tecnologías en el desarrollo del currículo escolar. La inclusión de las Tecnologías de la

${ }^{1}$ Universidade do Minho, Portugal. Professora no Ensino Básico e Secundário e Pós-doc em Ciências da Educação no Centro de Investigação em Estudos da Criança na Universidade do Minho. Doutora em Ciências da Educação.

${ }^{2}$ Universidade do Minho, Portugal. Professora no Instituto de Educação e investigadora no Centro de Investigação em Estudos da Criança na Universidade do Minho. Doutora em Ciências da Educação.

${ }^{3} \mathrm{O}$ agrupamento de escolas é uma unidade organizacional do sistema educativo de Portugal, dotada de órgãos próprios de administração e gestão, constituída por estabelecimentos de educação pré-escolar e de um ou mais níveis e ciclos de ensino, a partir de um projecto pedagógico comum. 
Información y de la Comunicación (TIC), como componente del currículo de carácter transversal, y de acuerdo con la legislación en vigor portuguesa (despacho normativo $n^{o}$ 1-F / 2016, artículo 3) Es objeto de evaluación en las diversas disciplinas, y los criterios definidos por el consejo pedagógico de cada agrupación. Las investigaciones han subrayado la contribución de las tecnologías en la mejora de los aprendizajes de los alumnos y en el éxito escolar. Sin embargo, las perspectivas de los alumnos son poco investigadas, por lo que este estudio tiene como objetivo comprender las perspectivas de los alumnos de la enseñanza básica sobre esta problemática. Recogemos los datos a través de encuesta por cuestionario, junto a alumnos $(n=233)$ de la Enseñanza Básica. Los alumnos señalan que acceden y utilizan las tecnologías para fines diversos: acceder al correo electrónico, archivar documentos, utilizar la plataforma moodle y consultar el sitio web de la escuela, a pesar de que su frecuencia sigue siendo muy reducida. Consideran que el recurso a las TIC permite concluir las tareas escolares más rápidamente, facilita la colaboración entre alumnos y profesores, haciéndola también más eficaz con los encargados de educación, mejora los aprendizajes y, consecuentemente, interviene en el éxito educativo.

PALAVRAS CLAVE: Tecnología de la información y la comunicación. Enseñanza básica. Uso. Frecuencia y Éxito.

ABSTRACT: This paper presents the results of a study that identifies the perspectives of the students of basic education on the contribution of the technologies in the development of the school curriculum. The inclusion of Information and Communication Technologies (ICT), as a component of the transversal curriculum, and according to the current Portuguese legislation (normative dispatch no. 1-F / 2016, article 3), its use Is an object of evaluation in the various disciplines, and the criteria defined by the pedagogical council of each group. Research has highlighted the contribution of technologies to improving student learning and school success. However, the perspectives of the students are little investigated, so this study aims to understand the perspectives of elementary school students on this issue. We collected the data through a questionnaire survey, with students $(n=233)$ of Basic Education. Students report that they access and use the technologies for a variety of purposes: accessing e-mail, archiving documents, using the moodle platform and consulting the school's website, although their frequency is still very small. They consider that the use of ICT makes it possible to complete school tasks more quickly, to facilitate collaboration between pupils and teachers, to make it more effective with parents, to improve learning and, consequently, to intervene in educational success.

KEYWORDS: Information and communication technology. Basic education. Use. Frequency and Success.

\section{Introdução}

Refletir sobre a problemática da inserção das tecnologias da informação e da comunicação nas escolas é, desde logo, perceber o uso que delas se faz, que papel têm no 
processo de desenvolvimento curricular e de que forma elas geram transformações na educação e, consequentemente, na sociedade. Numa sociedade tecnológica, instrumentos como computadores e dispositivos móveis fazem parte do quotidiano de qualquer sala de aula, pois são o meio mais importante de acesso e de apropriação do conhecimento, de desenvolver competências transversais e de fomentar uma educação empreendedora, pelo que a dimensão pedagógica do seu uso se revela fundamental.

Neste sentido, procuramos compreender as perspetivas dos alunos sobre o papel das Tecnologias da Informação e da Comunicação (TIC) na melhoria das suas aprendizagens e se há relação entre estas e o sucesso escolar. Questionamos se as tecnologias são facilitadoras na aquisição de novos conhecimentos e competências, na realização das tarefas escolares, na melhoria dos seus resultados, na promoção da autoaprendizagem, no recurso a redes de colaboração e, ainda, se facilitam o trabalho colaborativo entre alunos, professores e encarregados de educação.

\section{Integração das TIC no currículo}

Como forma de melhor enquadrar este estudo, fazemos uma abordagem, ainda que breve, à integração das TIC no currículo escolar pois, além de constituirem objeto de avaliação nas diversas disciplinas, têm colocado desafios pedagógicos aos professores e aos alunos, no processo de desenvolvimento curricular.

As investigações têm salientado o impacto positivo das tecnologias na aprendizagem e, consequentemente, no sucesso escolar (MORAIS, 2014; OLIVEIRA, 2012; RAMOS 2004; RAPOSO 2001). As competências digitais e atitudes perante as TIC, o uso das TIC dentro e fora da sala pelos alunos, o uso profissional das TIC dentro e fora da sala pelos professores, as atitudes dos professores perante as TIC, a infraestrutura, conetividade e acesso às TIC nas escolas, foram áreas de investigação tratadas no estudo "Survey of Schools: ICT in Education" realizado pela Comissão Europeia (2013). Este estudo, sobre a utilização das TIC nas Escolas Europeias, no ano letivo de 2011/2012, abrangeu 190 mil alunos, diretores de escola e professores, contou com a participação de 31 países europeus e desenvolveu indicadores de recolha e análise de dados sobre o uso, competências e atitudes dos alunos perante as TIC. Dada a relevância de algumas conclusões para o nosso estudo, passamos a elencá-las: quatro em cada cinco alunos estão 
em escolas onde os professores usam as TIC no ensino; a quase totalidade dos alunos europeus está em escolas onde os professores usam as TIC para preparar as aulas; não há uma correlação positiva entre a disponibilização de computadores e a frequência do seu uso pelos alunos. No entanto, os diretores de escola e, principalmente, os professores, consideraram que equipamentos de TIC em quantidade insuficiente é o maior obstáculo ao seu uso, nomeadamente, nos primeiros níveis de escolaridade; a prática de atividades baseadas nas TIC é mais baixa nos alunos do que nos professores; um em cada oito alunos europeus está numa escola onde existe um forte incentivo e apoio dos professores no uso das TIC; uma em cada quatro escolas onde os professores têm confiança no uso das TIC têm elevados níveis de acesso àquelas e poucos obstáculos ao seu uso nas aulas; um em cada três alunos tem elevados níveis de acesso e uso das TIC em casa e na escola. Não foi encontrada uma correlação positiva entre elevados níveis de disponibilização de TIC e confiança, uso e atitudes de professores e alunos.

Face a estes resultados, o focus da política educativa deve estar relacionado com a gestão efetiva da aprendizagem e não com o fornecimento de TIC, pois a presença de ambientes de aprendizagem virtual nas escolas está a aumentar rapidamente e existe um elevado uso das TIC em casa, nomeadamente, em atividades relacionadas com entretenimento, tais como música, notícias, procura de informação online. A gestão das aprendizagens deverá, assim, ter em conta a aprendizagem informal fora da escola, e o interesse dos alunos numa aprendizagem autodirigida (MOREIRA, 2013, p.19).

A tarefa do professor será a de criar situações que envolvam os alunos na sua aprendizagem para os ajudar a desenvolver o pensamento crítico, devendo as TIC "ser integradas de forma contextualizada na prática pedagógica, que faça sentido na forma de ensinar do professor e que cause algum impacto na aprendizagem do aluno" (MORAIS, 2014, p.41), sendo que o fundamental não é viabilizar o acesso à tecnologia aos alunos, mas saber utilizá-la de maneira mais ampla para as finalidades da escola. (ALMEIDA, 2010, p. 1). As potencialidades pedagógicas da WEB 2.0, pelo surgimento de redes colaborativas de conhecimento, onde assuntos diversos são postos em discussão e o conhecimento é organizado de forma contínua (CARVALHO, 2012), devem ser exploradas pelo professor na abordagem dos conteúdos. Ferramentas como Delicious, GoogleDocs, Flickr, YouTube, Blogger, Wikipédia, Twitter, Facebook, Podcast, Dandelife, Goowy, Google+, e outras surgem com uma proposta de fácil aplicação, permitindo a comunicação e cooperação entre os milhares de emissores e recetores. 


\section{Opções metodológicas}

A metodologia designa o conjunto de métodos selecionados segundo uma determinada conceção, tem implícita uma ideologia e propõe-se ajudar a conduzir todo o processo de investigação. Neste estudo, recorremos a uma metodologia de natureza quantitativa (MOREIRA, 2006), que constitui um processo sistemático de recolha de dados observáveis e quantificáveis sobre um conjunto alargado de pessoas, relativos a um certo número de questões pré-determinadas (COUTINHO, 2014). O inquérito por questionário (GHIGLIONE e MATALON, 2001) com itens fechados e escala com três ou cinco níveis de resposta, foi o instrumento de recolha de dados que permitiu quantificar as informações e objetivar os resultados, evitando distorções de análise e de interpretação.

\section{Objetivos}

Para compreender, quer as perspetivas dos alunos sobre o papel das Tecnologias da Informação e da Comunicação (TIC) na melhoria das suas aprendizagens, quer a existência da relação entre estas e o sucesso escolar, formulamos os seguintes objetivos: a) analisar as perceções dos alunos sobre o acesso e a utilização das TIC; b) verificar a frequência da sua utilização; c) identificar as perspetivas dos alunos sobre o papel das TIC na melhoria das suas aprendizagens; d) compreender a relação entre as TIC e o sucesso escolar.

\section{Contextualização e caracterização dos alunos participantes no estudo}

Este estudo foi realizado no ano letivo 2015/2016, num agrupamento de escolas localizado na zona norte de Portugal, cujo território educativo abrange três (3) estabelecimentos de educação pré-escolar, cinco (5) do $1^{\circ}$ Ciclo e um (1) do $2^{\circ}$ e $3^{\circ}$ Ciclos do Ensino Básico (sede do agrupamento). O estudo foi realizado com alunos que frequentavam o $3^{\circ}$ ciclo do Ensino Básico $\left(7^{\circ}, 8^{\circ}\right.$ e $9^{\circ}$ anos de escolaridade), num total de 233, que aceitaram participar no estudo.

Na tabela 1, apresentamos a caracterização dos alunos. Desse modo, os alunos tinham idades compreendidas entre os 12 e os 17 anos, assim distribuídos: 48 tinham 12 
anos (20,6\%), 58 tinham 13 anos (24,9\%), 66 tinham 14 anos (28,3\%), 41 tinham 15 anos $(17,6 \%)$ e, em menor número e percentagem, situavam-se 15 alunos nos 16 anos $(6,4 \%)$ e 5 alunos nos 17 anos $(2,1 \%)$. Quanto ao ano de escolaridade, $41,6 \%$ frequentavam o $7^{\circ}$ ano, $31,4 \%$ o $8^{\circ}$ ano e $27,3 \%$ frequentavam o $9^{\circ}$ ano.

Relativamente ao gênero, mais de metade dos alunos participantes $(53,6 \%)$ pertenciam ao gênero feminino e $46,4 \%$ ao gênero masculino (Tabela 1 ).

Tabela 1: Caracterização dos participantes: idade e ano de escolaridade

\begin{tabular}{|c|c|c|c|c|c|c|c|}
\hline \multicolumn{8}{|c|}{ Alunos $N=233($ n e $\%)$} \\
\hline Idade & & $\begin{array}{r}12 \\
\text { anos }\end{array}$ & $\begin{array}{r}13 \\
\text { anos }\end{array}$ & $\begin{array}{c}14 \\
\text { anos }\end{array}$ & $\begin{array}{c}15 \\
\text { anos }\end{array}$ & $\begin{array}{c}16 \\
\text { anos }\end{array}$ & $\begin{array}{c}17 \\
\text { anos }\end{array}$ \\
\hline & $\mathrm{n}$ & 48 & 58 & 66 & 41 & 15 & 5 \\
\hline & $\%$ & 20,6 & 24,9 & 28,3 & 17,6 & 6,4 & 2,1 \\
\hline Ano de escolaridade & \multicolumn{7}{|c|}{ Alunos N=233 (n e \%) } \\
\hline \multirow[t]{2}{*}{$7^{\circ}$ ano } & $\mathrm{n}$ & 48 & 28 & 10 & 11 & & \\
\hline & $\%$ & 20,6 & 12,0 & 4,3 & 4,7 & & \\
\hline \multirow{2}{*}{$8^{\circ}$ ano } & $\mathrm{n}$ & & 30 & 28 & 10 & 5 & \\
\hline & $\%$ & & 12,9 & 12,0 & 4,4 & 2,1 & \\
\hline \multirow[t]{2}{*}{$9^{\circ}$ ano } & $\mathrm{n}$ & & & 28 & 20 & 10 & 5 \\
\hline & $\%$ & & & 12,0 & 8,5 & 4,4 & 2,1 \\
\hline
\end{tabular}

Fonte: Elaboração própria.

\section{Métodos, Instrumento e técnicas de recolha de dados}

Elaboramos um inquérito por questionário (MOREIRA, 2006; GHIGLIONE e MATALON, 2001; HILL e HILL, 2009) com três dimensões: acesso e utilização das TIC nas tarefas escolares, com 10 itens de resposta fechada; a frequência de utilização das TIC nas tarefas escolares, com 10 itens; e o contributo das TIC para a melhoria das aprendizagens, com 11 itens de resposta fechada. O questionário foi validado por especialistas e, seguidamente, por um estudo piloto, tendo a investigadora obtido a autorização da direção da escola e dos Encarregados de Educação para os passar aos alunos, que responderam individualmente. 
Para o tratamento dos dados, utilizamos um programa informático, designado por SPSS, versão 24 para Windows, e recorremos à estatística descritiva para a sua análise.

\section{Apresentação e discussão dos resultados}

\section{Dimensão 1 - Acesso e utilização das TIC nas tarefas escolares}

Tal como se pode observar na tabela 2 , relativamente à acessibilidade na utilização das ferramentas de produtividade Excel, Word e Power Point, a quase totalidade dos alunos $(96,6 \%)$ refere que tem acesso e que utiliza estas ferramentas; $75,5 \%$ dos alunos acede e utiliza programas multimedia, assim como programas administrativos internos, tais como: GIAE Online, etc; $74,7 \%$ tem acesso e utiliza os quadros interativos. Uma percentagem significativa $(49,4 \%)$ desconhece o Software_Geogebra_Cabri e 38,6\% dos alunos não utilizam sistemas de arquivo de documentos online, tais como Dropbox e Google Drive, sendo que $27 \%$ não os conhece. A utilização da página (website) da escola é mencionada por 80,3\% dos alunos inquiridos; apenas 10,3\% refere que a desconhece. Quanto ao acesso e utilização do Sistema de Correio eletrônico, 95,3\% dos alunos refere utilizá-lo. Relativamente à videoconferência ou comunicação síncrona (e.x.: Skype, Google Talk), 32,2\% dos alunos não acede e 10,7\% desconhece esses recursos. Por último, 88\% dos alunos inquiridos afirmam conhecer e aceder a plataformas de gestão de conteúdos online, tais como o Moodle, Blogs, Wikis.

Tabela 2: Acesso e utilização das TIC nas tarefas escolares

\begin{tabular}{|c|c|c|c|c|c|c|}
\hline \multicolumn{7}{|c|}{$\begin{array}{c}\text { Alunos } N=233 \\
\% \text { de sujeitos }\end{array}$} \\
\hline Acceso/utilização & & $\underset{(1)}{\operatorname{Sim}}$ & $\begin{array}{l}\text { Não } \\
(2)\end{array}$ & $\begin{array}{c}\text { Desconheço } \\
\text { (3) }\end{array}$ & Média & $\begin{array}{l}\text { Desvio } \\
\text { Padrão }\end{array}$ \\
\hline $\begin{array}{c}\text { 1-Ferramentas de produtividade Power - Point/ } \\
\text { Word/Excel }\end{array}$ & $\%$ & 96,6 & 1,3 & 2,1 & 1,068 &, 365 \\
\hline 2-Programas multimédia; Vídeos & $\%$ & 75,5 & 12,5 & 12 & 1,364 & ,688 \\
\hline 3-Quadro interativo & $\%$ & 74,7 & 13,3 & 12 & 1,373 & ,690 \\
\hline 4-Software_Geogebra_Cabri & $\%$ & 28,8 & 21,9 & 49,4 & 2,206 &, 861 \\
\hline
\end{tabular}




\begin{tabular}{|c|c|c|c|c|c|c|}
\hline $\begin{array}{l}\text { 5-Programas administrativos internos como: GIAE } \\
\text { Online etc. }\end{array}$ & $\%$ & 75,5 & 7,3 & 17,2 & 1,416 & ,767 \\
\hline $\begin{array}{l}\text { 6-Sistemas de arquivo de documentos online } \\
\text { como: Dropbox, drive }\end{array}$ & $\%$ & 34,3 & 27 & 38,6 & 2,043 & 854 \\
\hline 7-O website da escola. & $\%$ & 80,3 & 9,4 & 10,3 & 1,300 & 646, \\
\hline 8-Sistema de Correio electrónico & $\%$ & 95,3 & 3,4 & 1,3 & 1,060 & 287 \\
\hline $\begin{array}{l}\text { 9-videoconferência ou comunicação síncrona como } \\
\text { Skype, Google Talk, etc }\end{array}$ & $\%$ & 56,7 & 32,2 & 10,7 & 1,549 & ,700 \\
\hline $\begin{array}{l}\text { 10-Plataformas de gestão de conteúdos online } \\
\text { como o Moodle, Blogs, Wikis, }\end{array}$ & $\%$ & 88 & 6 & 6 & 1,180 &, 518 \\
\hline
\end{tabular}

Fonte: Elaboração própria.

\section{Dimensão 2- Frequência de utilização das TIC nas tarefas escolares}

Esta dimensão é constituída pelos itens que pretendem conhecer a frequência de utilização das TIC nas tarefas escolares. Cada item tem uma escala com 5 possibilidades de respostas, assim distribuídas: 1 (=1 vez por mês), 2 (=1 vez por semana), 3 (=1 vez por dia), 4 (=várias vezes dia) e 5(=não uso).

Como se pode observar pela tabela 3, relativamente ao Powerpoint, ao Word e ao Excel, 48,9\% dos alunos refere que utiliza estas ferramentas de produtividade uma vez por mês $(20,6 \%), 37,3 \%$ refere a sua utilização uma vez por semana e 3,9\% refere que não usa estes recursos. Esta utilização parece estar altamente dependente da orientação seguida pelos professores, sobretudo em algumas tarefas escolares, tal como sustentam outros estudos (COSTA, 2008).

No que concerne à frequência de utilização de software específico da área curricular, referem que utilizam uma vez por mês 50,2\% dos inquiridos, uma vez por semana $15,5 \%$, e não o usam $26,2 \%$ dos inquiridos. Quanto ao quadro interativo, verificase uma situação análoga, pois 47,2\% utilizam-no uma vez por mês, enquanto que 23,2\% o utilizam uma vez por semana e $15 \%$ referem que não o utilizam. Tal como demonstram alguns estudos (Costa, 2010, p.934), o software específico da área curricular deveria ser mais explorado por parte dos professores para a motivação dos alunos para determinados temas, tornando-os mais apelativos.

Relativamente aos programas administrativos internos, como: GIAE Online e website da escola, 52,4\% dos alunos inquiridos consultam o GIAE online pelo menos 1 vez 
por mês e 20,6\% uma vez por semana; apenas $18,5 \%$ não o consulta nunca. O website da escola é consultado, pelo menos uma vez por mês, por 47,6\%, e uma vez por semana por $32,6 \%$ dos inquiridos.

Os sistemas de videoconferência ou comunicação síncrona, tais como Skype, são utilizados pelo menos uma vez por mês por 30,6\% dos inquiridos, uma vez por semana por $24 \%$, e $6,9 \%$ refere que não utilizam nunca.

Sobre as plataformas de gestão de conteúdos online, tais como Moodle, Blogs, Wikis, 45,5\% dos inquiridos utilizam-nas uma vez por mês e 40,3\% uma vez por semana. Estes dados totalizam $85,8 \%$ de utilização da plataforma moodle, uma vez que os alunos do $2^{\circ}$ e $3^{\circ}$ ciclos são todos registrados nesta plataforma, sustentando uma metodologia de ensino e aprendizagem que organiza o espaço de interação de acordo com uma dada intencionalidade e promove a autoaprendizagem com recurso a uma rede de colaboração (LACERDA, 2007).

Programas multimédia e vídeos são utilizados por $12 \%$ dos inquiridos várias vezes por dia, por $36,5 \%$, pelo menos uma vez por mês, e $33 \%$ fazem-no uma vez por semana.

Salientamos que o correio eletrônico é consultado uma vez por semana por 39,9\% dos inquiridos, uma vez por dia por 19,3\%, e apenas 13,7\% referem consultá-lo várias vezes por dia.

Tabela 3: Frequência de utilização das TIC nas tarefas escolares

\begin{tabular}{|c|c|c|c|c|c|c|c|c|}
\hline \multicolumn{9}{|c|}{$\begin{array}{c}\text { Alunos } \mathrm{N}=233 \\
\% \text { de sujeitos }\end{array}$} \\
\hline Itens & & $\begin{array}{l}\text { 1vez } \\
\text { /mês } \\
(1)\end{array}$ & $\begin{array}{l}1 \text { vez/ } \\
\text { /sem( } \\
2)\end{array}$ & $\begin{array}{l}1 \mathrm{vez} \\
/ \mathrm{dia} \\
\text { (3) }\end{array}$ & $\begin{array}{l}\text { Varias } \\
\text { /dia } \\
(4)\end{array}$ & $\begin{array}{l}\text { Não } \\
\text { uso } \\
\text { (5) }\end{array}$ & Média & $\begin{array}{l}\text { Desvio } \\
\text { Padrão }\end{array}$ \\
\hline 1-Power - Point/ Word/Excel & $\%$ & 48,9 & 37,3 & 5,2 & 4,7 & 3,9 & 1,772 & 1,014 \\
\hline $\begin{array}{c}\text { 2-Software } \\
\text { Geogebra,Cabri, TIC, etc. }\end{array}$ & $\%$ & 50,2 & 15,5 & 6 & 2,1 & 26,2 & 2,386 & 1,693 \\
\hline 3-Quadro interactivo & $\%$ & 47,2 & 23,2 & 7,7 & 6,9 & 15 & 2,193 & 1,465 \\
\hline $\begin{array}{l}\text { 4-Programas administrativos } \\
\text { internos como: GIAE Online etc. }\end{array}$ & $\%$ & 52,4 & 20,6 & 6,4 & 2,1 & 18,5 & 2,137 & 1,525 \\
\hline 5-Programas multimédia; Vídeos & $\%$ & 36,5 & 33 & 12,4 & 12 & 6 & 2,497 & 1,313 \\
\hline $\begin{array}{l}\text { 6-Sistemas de arquivo de } \\
\text { documentos online como: } \\
\text { Dropbox, drive }\end{array}$ & $\%$ & 52,4 & 13,3 & 5,6 & 5,6 & 23,2 & 2,3391 & 1,668 \\
\hline 7-O website da escola. & $\%$ & 47,6 & 32,6 & 9 & 3 & 7,7 & 1,905 & 1,174 \\
\hline
\end{tabular}




\begin{tabular}{|c|c|c|c|c|c|c|c|c|}
\hline & & & & & & & \\
\hline $\begin{array}{c}\text { 8-Sistema de Correio eletrónico } \\
\text { como Gmail, Hotmail, }\end{array}$ & $\%$ & 23,6 & 39,9 & 19,3 & 13,7 & 3,4 & 2,334 & 1,086 \\
\hline $\begin{array}{c}\text { 9-Sistemas de videoconferência } \\
\text { ou comunicação síncrona como } \\
\text { Skype, Google Talk, etc }\end{array}$ & $\%$ & 30,9 & 24 & 16,3 & 21,9 & 6,9 & 2,497 & 1,313 \\
\hline $\begin{array}{c}\text { 10-Plataformas de gestão de } \\
\text { conteúdos online como o Moodle, } \\
\text { Blogs, Wikis, etc }\end{array}$ & $\%$ & 45,5 & 40,3 & 6,4 & 2,6 & 5,2 & 1,815 & 1,027 \\
\hline
\end{tabular}

Fonte: Elaboração própria.

Dimensão 3 - O contributo das TIC para a melhoria das aprendizagens

Esta dimensão integra os 11 itens que pretendem avaliar a perspectiva dos alunos quanto ao contributo das TIC para a melhoria das aprendizagens. Os inquiridos posicionavam-se de acordo com a escala de 5 pontos, em que 1 corresponde a discordar totalmente, 2 a discordar, 3 a nem concordar nem discordar, 4 a concordar e 5 a concordar totalmente.

Como podemos observar na tabela 4 , os alunos têm uma perspetiva muito positiva relativamente ao contributo das TIC no seu percurso escolar e, consequentemente, na melhoria das suas aprendizagens.

Assim, questionados sobre se o recurso às TIC permite concluir as tarefas da escola mais rapidamente, $76,8 \%$ dos inquiridos concorda e concorda totalmente, somente $6 \%$ discorda e discorda totalmente, situando-se a média em 4,03 e o desvio padrão em ,96.

Questionados sobre se as TIC melhoram os seus resultados escolares, 50,7\% afirma que concorda ou concorda totalmente, mas realçamos que $33 \%$ não concorda nem discorda, sendo que este resultado manifesta que um terço dos alunos não relaciona a melhoria dos resultados escolares com o recurso às TIC. A média situa-se em 3,54 e o desvio padrão em 1,1 .

Quanto à utilidade das TIC em todas as práticas escolares, 52,6\% dos alunos refere que concorda ou concorda totalmente, $29,2 \%$ não concorda nem discorda, situando-se a média em 3,75 e o desvio padrão em ,95.

Relativamente à relação entre o uso das TIC e a promoção da autoaprendizagem com recurso a redes de colaboração, os alunos inquiridos têm uma atitude maioritariamente positiva $(63,6 \%)$, apesar de ser significativa a percentagem de alunos (30\%) que nem concorda nem discorda, situando-se a média em 3,77 e o desvio padrão em ,90. A maioria 
dos inquiridos $(66,5 \%)$ concorda ou concorda totalmente que o recurso às TIC "facilita o trabalho colaborativo entre alunos e professores", contudo, 28,3\% dos alunos não concorda nem discorda, não relacionando as TIC com o aumento do trabalho colaborativo entre alunos e professores. A média situa-se em 3,8 e a diferença em relação à média é de ,88.

$\mathrm{Na}$ opinião de uma grande maioria dos alunos inquiridos $(71,7 \%)$, o recurso às TIC "facilita a aprendizagem"; apenas 6,9\% referem que discordam e discordam totalmente. A média é de 3,87 e o desvio padrão de ,94. Este resultado realça a perspetiva de Costa (2010, p.934), quando refere "não é o ensino das tecnologias o mais importante, mas sim, a aprendizagem com tecnologias".

Continuando a observar a tabela 4, constatamos que 69,9\% dos alunos concorda e concorda totalmente que é fundamental na escola o correio eletrônico e outras redes sociais. Assim, os alunos reconhecem grande interesse na comunicação através do correio eletrônico e das redes sociais, mas há ainda uma percentagem significativa de alunos $(22 \%)$ que não concorda nem discorda.

$\mathrm{O}$ recurso às TIC torna mais eficaz a comunicação entre professores, alunos e encarregados de educação para 57,5\% dos alunos, situando-se a média em 3,8 e a diferença em relação à média em ,88. De fato, a comunicação é facilitada para todos, com possíveis ganhos em muitas circunstâncias curriculares.

Sobre se o recurso às TIC melhora a informação em todas as atividades escolares, $67 \%$ dos inquiridos concorda ou concorda totalmente, embora $27,9 \%$ se mantenham numa atitude neutra. $\mathrm{O}$ resultado mostra que a informação por estes meios tecnológicos circula corretamente por todos os canais de informação da escola.

Os inquiridos consideram que o recurso às TIC lhes proporcionam motivação que ajuda a melhorar as aprendizagens, pois $62,7 \%$ concorda e concorda totalmente com tal afirmação, mas 30,5\% mantém uma posição neutra, situando-se a média em 3,76.

A maioria dos inquiridos $(58,8 \%)$ também considera que as TIC permitem gerir melhor os materiais de aprendizagem, apesar de 36,9\% dos alunos ter se posicionado no nem concordo nem discordo. Este é o item que apresenta a média mais baixa, 3,75.

Tabela 4: Contributo das TIC na melhoria das aprendizagens 


\begin{tabular}{|c|c|c|c|c|c|c|c|c|}
\hline \multicolumn{9}{|c|}{$\begin{array}{c}\text { Alunos } N=233 \\
\% \text { de sujeitos }\end{array}$} \\
\hline $\begin{array}{l}\text { Itens } \\
\text { O recurso às TIC: }\end{array}$ & & $\begin{array}{c}\text { Discor/ } \\
\text { Totalm } \\
\text { ente } \\
(1) \\
\end{array}$ & $\begin{array}{c}\text { Discordo } \\
\text { (2) } \\
\end{array}$ & $\begin{array}{c}\text { N/Concor } \\
\text { N/discord } \\
o \\
(3) \\
\end{array}$ & $\begin{array}{c}\text { Concordo } \\
\\
(4) \\
\end{array}$ & $\begin{array}{l}\text { Concor/ } \\
\text { totalment } \\
\mathrm{e} \\
(5)\end{array}$ & Média & $\begin{array}{l}\text { Desvio } \\
\text { Padrão }\end{array}$ \\
\hline \multirow{2}{*}{$\begin{array}{l}1 \text { - permite concluir as } \\
\text { tarefas da escola mais } \\
\text { rapidamente. }\end{array}$} & $\begin{array}{c}\mathrm{N}^{\circ} \\
\text { alunos }\end{array}$ & 7 & 7 & 40 & 97 & 82 & 4,03 & ,96 \\
\hline & $\%$ & 3 & 3 & 17,2 & 41,6 & 35,2 & & \\
\hline \multirow[t]{2}{*}{$\begin{array}{l}2 \text { - Melhora os meus } \\
\text { resultados escolares. }\end{array}$} & $\begin{array}{c}\mathrm{N}^{\circ} \\
\text { alunos }\end{array}$ & 7 & 31 & 77 & 64 & 54 & 3,54 & 1,1 \\
\hline & $\%$ & 3 & 13,3 & 33 & 27,5 & 23,2 & & \\
\hline \multirow[t]{2}{*}{$\begin{array}{l}\text { 3- É muito útil em todas } \\
\text { as práticas escolares. }\end{array}$} & $\begin{array}{c}\mathrm{N}^{\circ} \\
\text { alunos }\end{array}$ & 5 & 14 & 68 & 93 & 53 & 3,80 & ,95 \\
\hline & $\%$ & 2,1 & 6 & 29,2 & 39,9 & 22,7 & & \\
\hline \multirow{2}{*}{$\begin{array}{l}\text { 4- Promove a } \\
\text { autoaprendizagem com } \\
\text { recurso a redes de } \\
\text { colaboração. }\end{array}$} & $\begin{array}{c}\mathrm{N}^{\circ} \\
\text { alunos }\end{array}$ & 4 & 11 & 70 & 98 & 50 & 3,77 & ,90 \\
\hline & $\%$ & 1,7 & 4,7 & 30 & 42,1 & 21,5 & & \\
\hline \multirow{2}{*}{$\begin{array}{l}\text { 5- Facilita o trabalho } \\
\text { colaborativo entre alunos } \\
\text { e professores. }\end{array}$} & $\begin{array}{c}\mathrm{N}^{\circ} \\
\text { alunos }\end{array}$ & 3 & 9 & 66 & 99 & 56 & 3,77 & ,90 \\
\hline & $\%$ & 1,3 & 3,9 & 28,3 & 42,5 & 24 & & \\
\hline \multirow[t]{2}{*}{$\begin{array}{l}\text { 6- Facilita a } \\
\text { aprendizagem. }\end{array}$} & $\begin{array}{c}\mathrm{N}^{\circ} \\
\text { alunos }\end{array}$ & 7 & 9 & 50 & 106 & 61 & 3,87 & ,94 \\
\hline & $\%$ & 3 & 3,9 & 21,5 & 45,5 & 26,2 & & \\
\hline \multirow{2}{*}{$\begin{array}{l}\text { 7- É fundamental na } \\
\text { escola o correio eletrónico } \\
\text { e as redes sociais. }\end{array}$} & $\begin{array}{c}\mathrm{N}^{\circ} \\
\text { alunos }\end{array}$ & 4 & 13 & 53 & 93 & 70 & 3,91 & ,95 \\
\hline & $\%$ & 1,7 & 5,6 & 22,7 & 39,9 & 30 & & \\
\hline \multirow{2}{*}{$\begin{array}{l}\text { 8- Torna mais eficaz a } \\
\text { comunicação entre } \\
\text { professores, alunos e } \\
\text { encarregados de educação. }\end{array}$} & $\begin{array}{c}\mathrm{N}^{\circ} \\
\text { alunos }\end{array}$ & 8 & 14 & 77 & 93 & 41 & 3,84 & ,88 \\
\hline & $\%$ & 3,4 & 6 & 33 & 39,9 & 17,6 & & \\
\hline \multirow{2}{*}{$\begin{array}{l}\text { 9- Melhora a informação } \\
\text { em todas as atividades } \\
\text { escolares. }\end{array}$} & $\begin{array}{c}\mathrm{N}^{\circ} \\
\text { alunos }\end{array}$ & 2 & 10 & 65 & 115 & 41 & 3,79 & ,81 \\
\hline & $\%$ & ,9 & 4,3 & 27,9 & 49,4 & 17,6 & & \\
\hline \multirow{2}{*}{$\begin{array}{l}\text { 10- Proporciona-me } \\
\text { motivação que me ajuda a } \\
\text { melhorar as } \\
\text { aprendizagens. }\end{array}$} & $\begin{array}{c}\mathrm{N}^{\circ} \\
\text { alunos }\end{array}$ & 2 & 14 & 71 & 98 & 48 & 3,76 & ,88 \\
\hline & $\%$ & ,9 & 6 & 30,5 & 42,1 & 20,6 & & \\
\hline \multirow{2}{*}{$\begin{array}{l}\text { 11- Permite gerir melhor } \\
\text { os materiais de } \\
\text { aprendizagem }\end{array}$} & $\begin{array}{c}\mathrm{N}^{\mathrm{o}} \\
\text { alunos }\end{array}$ & 2 & 8 & 86 & 88 & 49 & 3,75 & ,86 \\
\hline & $\%$ & ,9 & 3,4 & 36,9 & 37,8 & 21 & & \\
\hline
\end{tabular}

Fonte: Elaboração própria.

\section{Considerações finais}

A utilização das tecnologias no processo de ensino aprendizagem é, hoje, inquestionável por parte dos professores e alunos, pois é uma resposta necessária aos permanentes desafios de inovação e da mudança. 
Os alunos referem que utilizam as tecnologias para fins diversos: aceder ao email, arquivar documentos, utilizar a plataforma moodle e consultar a website da escola. Consultam, ainda, o programa administrativo GIAE-online, para o conhecimento do seu registo diário. No âmbito da sala de aula, o programa Geogebra e os quadros interativos são muitas vezes ignorados, pois a frequência de utilização é, ainda, muito reduzida.

Apesar destes recursos educativos disponíveis na instituição escolar, é preciso flexibilizar recursos, gerir, fazer acontecer e, sobretudo, adaptar práticas de ensinar e aprender.

Da análise da informação relativamente à perspectiva dos alunos sobre as TIC e a influência destas na melhoria das aprendizagens e, consequentemente, no sucesso escolar, observamos que a maioria dos alunos considera que as TIC contribuem para a melhoria das aprendizagens, pois $\mathrm{o}$ recurso a estas facilita a aprendizagem $\mathrm{e}$ promove $\mathrm{a}$ autoaprendizagem com recurso a redes de colaboração; logo, a informação que recebem através das TIC ajuda-os na sua aprendizagem e, consequentemente, no sucesso escolar. Os alunos reconhecem que a comunicação entre professores, alunos e encarregados de educação é eficaz, pelo que deve estar integrada de forma a apoiar e complementar as práticas letivas para o seu sucesso.

As tecnologias possuem um potencial determinante na motivação e na melhoria da aprendizagem, quer relativamente à participação dos alunos nas atividades escolares, quer na diversificação do ensino e das situações de aprendizagem, de acordo com os interesses e aptidões dos alunos, pois eles consideram que o recurso às TIC contribui para a sua motivação.

O fato de um terço dos alunos se posicionar numa posição neutra em muitos itens leva-nos a recomendar a realização de um estudo qualitativo para compreender as perspetivas destes alunos e a importância que a escola dá à integração das TIC no currículo.

Concluímos que as tecnologias facilitam as atividades práticas de caráter interdisciplinar e transdisciplinar e permitem a comunicação entre professores, alunos e encarregados de educação. Contudo, os resultados do estudo autorizam-nos a concluir que os professores têm, ainda, um longo caminho a percorrer para que as TIC sejam uma resposta aos permanentes desafios de inovação e de mudança, para que o currículo desenvolva competências transversais, fundamentais à empregabilidade e a uma educação empreendedora. Será importante que sejam exploradas as TIC como um recurso de 
aprendizagem significativa, se queremos passar de uma pedagogia de gavetas a uma pedagogia integrada, em que os saberes são mobilizáveis e cada professor poderá encontrar o polo de excelência que cada aluno possui, assim como o seu próprio polo de excelência, contribuindo também para o seu desenvolvimento pessoal e profissional.

\section{REFERÊNCIAS}

ALMEIDA. M. Web Currículo, caminhos e narrativas. In: Anais do II Seminário Web Currículo [online]. São Paulo: PUC-SP, p. 3, 2010.

COMISSÃO EUROPEIA. Survey of Schools: ICT in education. Luxembourg: European Comission. 2013.

CARVALHO, A . Web 2.0, educação a distância e o conceito de aprendizagem colaborativa na formação de professores. 2012. Disponível em:

$<$ http://anabeatrizgomes.pro.br/moodle/file.php/1/ARTIGOWEB2.0.pdf >. Acesso em: 10 abr. 2012.

COUTINHO, C. Metodologia de investigação em ciências sociais e humanas: Teoria e prática. Lisboa: Almedina, 2014.

COSTA, F. (coord.). Competências TIC, estudo de implementação (v. 1). Lisboa: Gabinete de Estatística e Planeamento da Educação, 2008.

COSTA, F. Metas de Aprendizagem na área das TIC: Aprender com Tecnologias. In Actas do I Encontro Internacional TIC e Educação, 2010 . Lisboa: Instituto Superior de Educação, p. 931-936, 2010.

GHIGLIONE, R.; MATALON, B. O Inquérito: teoria e prática. Oeiras: Celta Editora, 2001.

HILL, M.; HILL, A. Investigação por questionário. Lisboa: Edições Sílabo, 2009.

LACERDA, T. As plataformas de aprendizagem de b-learning: uma experiência na Biologia e Geologia de $10^{\circ}$ Ano. In: DIAS P., Freitas C. V., Silva B., Osório. A. \& RAMOS A. (orgs.). Atas XXIII Colóquio da AFIRSE Portugal da V Conferência Internacional de Tecnologias de Informação e Comunicação na Educação Challenges, 2007. Braga: Centro de Competência da Universidade do Minho, p. 314-325, 2007.

MORAIS, C. Práticas pedagógicas inovadoras com TIC. Tese de Mestrado. Lisboa 2014: Universidade de Lisboa. Disponível em:

<http://repositorio.ul.pt/bitstream/10451/10660/1/ulfpie046456_tm.pdf>. Acesso em: 20 mar. 2016 
MOREIRA, R. Importância das TIC e de recursos multimédia na aula de história. Dissertação de Mestrado de Educação e Multimédia . Instituto Superior Politécnico de Viseu 2013. Disponível em:

<http://repositorio.ipv.pt/bitstream/10400.19/2038/1/projeto_revis\%C3\%A3o_final\%2018 _02.pdf>. Acesso em: 12 jan. 2016

MOREIRA, J. Investigação quantitativa: Fundamentos e práticas. In J. A. de LIMA; J. PACHECO (eds.). Fazer investigação: contributos para a elaboração de dissertações e teses, p.41-84, Porto: Porto Editora, 2016.

OLIVEIRA, L. Plano Tecnológico da Educação e Educação Pública: Mitos (ensarilhados), limites e falsas promessas. In PARASKEVA, J. 2012. Currículo e tecnologia educativa, v. 3, ed. 1, p. 165-185, Mangualde: Edições Pedago, 2012.

PEREIRA, E.; OLIVEIRA, L. TIC na educação: desafios, conflitos e potencialidades pedagógicas com a web 2.0. Anais do $\mathbf{X}$ colóquio sobre questões curriculares \& VI colóquio luso brasileiro de currículo desafios contemporâneos no campo do currículo. Belo Horizonte - MG. Setembro, 2012.

RAMOS, I. Utilização da tabela periódica na internet com alunos do $9^{\circ}$ ano de escolaridade. M.Sc. Departamento de Química da FCUP, 2004.

RAPOSO, R. Sketchpad e a Trigonometria. Escola Superior de Educação de Setúbal 2001. [on-line]. Disnponível em: 〈http://www.ese.ips.pt/abolina/rota/relatos/nauala.html>. Acesso em: 10 ago. 2017.

DESPACHO NORMATIVO 1F/2016, de 5 de abril, Diário da República no . 66, 2a . Série. Regulamenta o regime de avaliação e certificação das aprendizagens. Disponível em: <https://www.dge.mec.pt/sites/default/files/JNE/despacho_normativo_1-g_2016.pdf>. Acesso em: 25 maio 2016

\section{Como referenciar este artigo}

SANTOS, Teresa Paulino; ALVES, Maria Palmira. O contributo das tecnologias no desenvolvimento do curriculo escolar: perspetivas dos alunos. Revista Ibero-Americana de Estudos em Educação, Araraquara, v. 12, n. esp. 2, p. 1554-1569, ago./2017. Disponível em: <http://dx.doi.org/10.21723/riaee.v12.n.esp.2.10309>. E-ISSN: 1982-5587.

Submetido em: 08/03/2017

Aprovação final em: 21/08/2017 